\title{
Joint effects of social class and community occupational structure on coronary mortality among black men and white men, upstate New York, 1988-92
}

\author{
D L Armstrong, D Strogatz, E Barnett, R Wang
}

See end of article for authors' affiliations

....................

Correspondence to: Dr D Armstrong, University at Albany, SUNY,

Department of

Epidemiology, SPH, One

University Place, Rensselaer NY 12144-3456, USA;

dla02@health.state.ny.us

Accepted for publication 14 November 2002

\begin{abstract}
Study objective: Occupational structure represents the unequal geographical distribution of more desirable jobs among communities (for example, white collar jobs). This study examines joint effects of social class, race, and county occupational structure on coronary mortality rates for men, ages 35-64 years, 1988-92, in upstate New York.

Design: Upstate New York's 57 counties were classified into three occupational structure categories; counties with the lowest percentages of the labour force in managerial, professional, and technical occupations were classified in category I, counties with the highest percentages were in category III. Age adjusted coronary heart disease (CHD) mortality rates, 35-64 years, (from vital statistics and census data) were calculated for each occupational structure category.

Main results: An inverse association between $\mathrm{CHD}$ mortality and occupational structure was observed among blue collar and white collar workers, among black men and white men, with the lowest CHD mortality observed among white collar, white men in category III (135/100 000). About two times higher mortality was observed among blue collar than white collar workers. Among blue collar workers, mortality was 1.3-1.8 times higher among black compared with white workers, and the highest rates were observed among black, blue collar workers (689/100 000). Also, high residential race segregation was shown in all areas.

Conclusions: Results suggest the importance of community conditions in coronary health of local populations; however, differential impact on subpopulations was shown. Blue collar and black workers may especially lack economic and other resources to use available community services and/or may experience worse working and living conditions compared with white collar and white workers in the same communities.
\end{abstract}

C apitalist development is based on unequal distributions of resources between social classes and geographically between areas, such that local labour and job markets range between predominantly skilled, white collar to mainly lower skilled, blue collar. The percentage of a county labour force in white collar jobs has been used as an indicator of occupational structure ${ }^{1-4}$ and this was positively associated with economic resources and the availability and diversity of community services. ${ }^{34}$ Furthermore, county occupational structure was associated with premature coronary heart disease (CHD) in several studies ${ }^{134}$ and stroke mortality ${ }^{2}$ and with the prevalence of cardiovascular risk factors such as overweight and exercise. ${ }^{4}$

Mechanisms for the influence of occupational structure on community coronary mortality rates include level of the local tax base and budget, and thus community infrastructure that provides for a wide range of conditions and opportunities facilitating healthy living (for example, reduced levels of crime; increased availability of grocery stores, medical care, sites for exercise/recreation; improved housing stock). ${ }^{34}$ Therefore, indicators of occupational structure represent advantages at an individual level afforded by better jobs, reflected in better cardiovascular risk profiles, and also at a community level because of greater numbers of better jobs in some communities, affecting overall resources and living conditions.

Numerous studies have shown an association between cardiovascular mortality, risk factors, and social class position. ${ }^{5-10}$ Mechanisms for the influence of individual social class position on cardiovascular health and risk factors include income and benefits, leisure time and time flexibility, class related advantages in forming and maintaining supportive social ties, and working conditions including job stress (for example, job control and demand). ${ }^{11}$ However, there is a deficit of theoretical discussion and empirical evidence linking economic organisation and processes with geographical aspects of social class and health disparities. In addition, little is known about the interface between socioeconomics of individuals and families and community environments, and differences in community effects for relatively advantaged and disadvantaged populations within communities. The purpose of this study was to report joint effects and potential mechanisms of individual social class, race and community occupational structure on levels of premature heart disease mortality.

\section{METHODS}

The proportion of the civilian, employed labour force in selected white collar occupations (that is, managerial, professional speciality, and technical occupations) was used to represent the occupational structure of counties in New York state. ${ }^{4}$ Information on the proportion of each county labour force in these selected white collar occupations was obtained from the US census in 1990. The 62 counties were ranked by the percentage of the labour force in white collar occupations, and the range between the first and the 99th centiles of the distribution was divided into three occupational structure categories of equal ranges of percentages. ${ }^{134}$ Counties with percentages of white collar workers below the first and above the 99th centiles of the distribution were included in categories I and III, respectively. Construction of the occupational structure categories based on equal divisions of the range of 


\begin{tabular}{|c|c|c|c|}
\hline & \multicolumn{3}{|c|}{ Occupational structure category } \\
\hline & 1 & II & III \\
\hline Percentage of total labour force in white collar occupations & $20-29$ & 30-39 & $40-50$ \\
\hline Black labour force & 20 & 24 & 28 \\
\hline White labour force & 37 & 46 & 52 \\
\hline Number of upstate NY counties & 37 & 17 & 3 \\
\hline New York upstate population (\%)* & $2660023(25)$ & $6773430(63)$ & 1234438 (12) \\
\hline Black population & $81574(11)$ & $521999(69)$ & $149880(20)$ \\
\hline White population & $2532807(26)$ & $6029421(63)$ & 1003868 (11) \\
\hline \multicolumn{4}{|l|}{ Percentage of population in each category } \\
\hline Living in an urban area $\dagger$ & 14 & 78 & 92 \\
\hline \multicolumn{4}{|l|}{ With a college degreef } \\
\hline Black men & 7 & 13 & 17 \\
\hline White men & 15 & 25 & 37 \\
\hline \multicolumn{4}{|l|}{ Unemployed§ } \\
\hline Black labour force & 16 & 12 & 9 \\
\hline White labour force & 7 & 6 & 4 \\
\hline \multicolumn{4}{|l|}{ Percentage of men in the labour force (ages 35-64) } \\
\hline Black men & 46 & 76 & 81 \\
\hline White men & 83 & 86 & 88 \\
\hline Median home value in dollars** & 62200 & 114700 & 282200 \\
\hline \multicolumn{4}{|l|}{ Per capita annual income in dollars } \\
\hline Total & 11772 & 17324 & 23479 \\
\hline Net from interest, dividends, rent & 702 & 1207 & 2107 \\
\hline \multicolumn{4}{|l|}{ Vehicles owned (per occupied housing unit) $\dagger \dagger$} \\
\hline Renters & 1.10 & 1.13 & 1.06 \\
\hline Home owners & 1.85 & 1.98 & 1.99 \\
\hline
\end{tabular}

*New York upstate population was 10667891 in 1990, US Census Bureau (STF3 file). †Urban areas have populations $\geqslant 50000$ or are located adjacent to metropolitan areas and have greater than 2500 population and at least 1000 persons per square mile. fFour year or higher college degree, among persons $\geqslant 25$ years old. §Unemployed are defined as non-institutionalised civilians, $\geqslant 16$ years of age, who were looking for work in the previous month and were available to accept work. Tlabour force participation defined as: employed civilians and military workers plus unemployed (see footnote §above) per race specific populations, men aged 35-64 years, in 1990 (STF4 Census file). ** Median value of owner occupied homes. ††Average numbers of vehicles owned per occupied owner and renter housing units.

percentage of managerial/ professional workers permits extrapolation of an observed pattern to the continuous variation in the occupational structure variable. The correlation between the 1980 and 1990 distributions is 0.90 , which indicates that the relative position of counties in the distribution was quite stable.

Two social classes, white collar and blue collar, were defined based on the "usual lifetime" occupation listed on the death certificate of decedents. As occupation on the death certificate was missing or described as "housewife" for $49 \%$ of women decedents, only men were included in this analysis, which is a limitation of this approach described previously. ${ }^{12}$ Furthermore, because occupation narratives from the death certificate of residents of New York City are not coded or computerised, this analysis was restricted to New York residents other than the five counties of New York City, which is commonly referred to as "upstate New York." The percentage of black decedents who were missing occupation information was $7 \%$ in category I, $18 \%$ in category II, and $15 \%$ in category III. The percentages for white decedents were $10 \%, 12 \%, 18 \%$, for categories I, II, and III, respectively.

Mortality rates were calculated for black men and white men, aged 35-64 years; this age group represents premature mortality. ${ }^{13}$ Deaths with underlying causes assigned to ICD-9 codes $^{14} 410-414,402,429.2$ were included as CHD deaths. Denominator data describing white collar and blue collar population counts at the county level were obtained by special request from the Bureau of Census, using the Public Use Microdata Sample (PUMS 5\%) for New York state in 1990. County level counts permitted the calculation of mortality rates simultaneously by social class and occupational structure category. Census data describe "current" or "most recent" occupation compared with "usual lifetime" occupation on the death certificate. However, relative stability over the course of the lifetime for the broad categories of white collar and blue collar was reported by a previous study. ${ }^{12}$ Therefore, census population counts may be used as estimates of the population at risk for calculation of mortality rates among white collar and blue collar workers.

CHD deaths and population counts for five year age groups, from 35-64 years, were summed within social class, race, and occupational structure categories, for 1988-92. Average annual age adjusted CHD mortality rates were calculated by social class, race, and occupational structure category for 1988-92, by the direct method using the 1970 US population as the standard. A mortality rate is not presented for white collar black men in occupational structure category I because of the small population size for this group $(n=1264)$ and too few deaths $(n=4)$ to generate a reliable mortality rate. ${ }^{15}$ As data for the calculation of rates represent complete death counts and as upstate New York counties were categorised rather than randomised into occupational structure categories, there is no basis for observed associations to be attributable to chance resulting from randomisation. Therefore, statistical testing of differences between categories was not conducted..$^{16-18}$

Data on urbanicity, income, unemployment, house values, education, and labour force participation were obtained from the 1990 US Census of Population and Housing. ${ }^{19}$ Population weighted averages of county data were calculated for each category of occupational structure. Information on earnings by industry were obtained from the 1990 Census City and County Data Book.

Income inequality was calculated, for each category of occupational structure using the "Robin Hood Index"..$^{20}$ The income inequality index represents the share of total income 


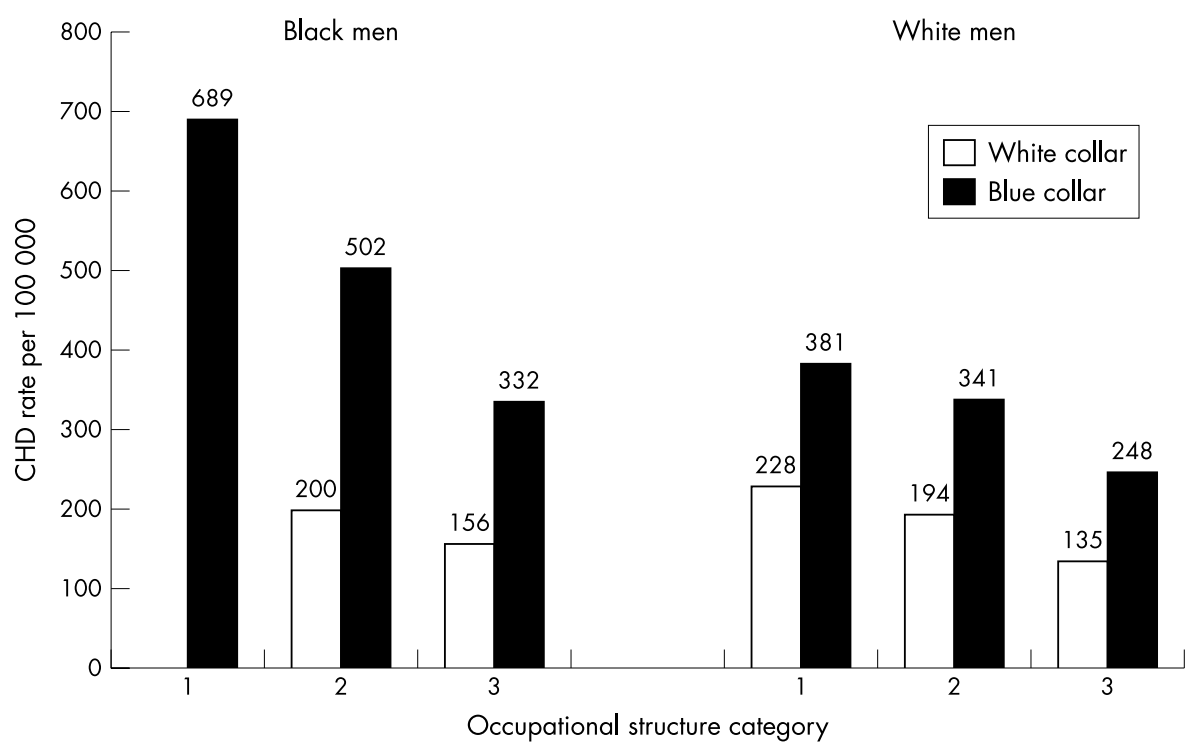

Figure 1 Age adjusted CHD mortality among upstate New York men, ages 35-64, 1988-92, by occupational structure, class, race. that would need to be transferred from those above the mean level of income to those below the mean, and therefore achieve equality in the distribution of income within each occupational structure category.

Residential racial segregation was calculated by a previously published method, ${ }^{21}$ and this same approach was used to calculate residential class segregation. County residential race segregation indices were population weighted by the black population and combined into an overall residential race segregation index for each occupational structure category. The residential race segregation index represents the percentage of the black population that would need to change their census tract of residence so that all tracts reflect the overall percentage of black population in the county. Residential class segregation was calculated based on the percentage of the population in selected white collar occupations (that is, managerial, professional speciality, and technical occupations). County residential class segregation indices were population weighted by the county population and combined into an overall residential class segregation index for each occupational structure category. The residential class segregation index represents the percentage of "upper" white collar workers that would need to change their census tract of residence so that all tracts reflect the overall percentage of "upper" white collar workers in the county.

\section{RESULTS}

In 1990, the proportion of the labour force in managerial/ professional occupations in upstate New York counties ranged from $20 \%$ to $50 \%$ (table 1). Category I represented counties with the smallest proportions of managerial/professional workers, $20 \%-29 \%$, and category III represented counties with the largest proportion of managerial/professional workers, $40 \%-50 \%$. However, percentages of black workers in managerial/ professional jobs ranged only between $20 \%$ and $28 \%$ in upstate New York in 1990. Category I represented 25\% of the population of upstate New York and $14 \%$ of residents in these counties lived in urban areas, compared with $92 \%$ of category III residents. The proportion of the population 25 years and older holding a (bachelors or higher) college degree was two times greater in category III (35\%) compared with category I counties (14\%) (data not shown). Furthermore, there were over two times the percentage of college educated among white compared with black men in all occupational structure categories. Labour force statistics reveal decreasing unemployment with increasing occupational structure. However, at least two times the unemployment among black men compared with white men in all occupational structure categories is shown.

Home values are an indicator of community economic resources, as a local tax base, which supports services such as schools and the local health department, is primarily based on property values. Median home values were 4.5 times the value in category III compared with category I. This is also related to average annual per capita income, which was two times the level in category III compared with category I, and per capita income from capital investment resources (stocks, dividends, rent) was three times greater in category III compared with category I counties.

Table 2 Age adjusted CHD mortality rates*, death and population counts among black men and white men by occupational class and occupational structure category, 1988-1992

\begin{tabular}{llll}
\hline & \multicolumn{2}{l}{ Occupational structure category } & \\
\cline { 2 - 4 } & $\mathrm{I}$ & II & III \\
\hline White collar & $-\dagger(4 / 1264) \ddagger$ & $200(119 / 19760)$ & $156(41 / 7163)$ \\
Black men & $228(1103 / 139350)$ & $194(3762 / 534576)$ & $135(598 / 109714)$ \\
White men & - & 1.03 & 1.16 \\
Black/white ratio & $689(75 / 3426)$ & $502(551 / 31779)$ & $332(124 / 9551)$ \\
Blue collar & $381(2506 / 193215)$ & $341(4602 / 364945)$ & $248(545 / 50690)$ \\
Black men & 1.81 & 1.47 & 1.34 \\
White men & Black/white ratio & &
\end{tabular}

*Age adjusted rates per 100000 , for ages 35 to 64 years, by the direct method of adjustment, using the 1970 US population as the standard. †Rate not calculated, due to too few deaths. $¥$ Number of deaths/race specific population counts, men ages $35-64$, shown in parentheses. 
Figure 1 shows an inverse association between CHD mortality and occupational structure among blue collar and white collar workers, among black men and white men. Therefore, the lowest CHD mortality rates were observed in occupational structure category III, which had the greatest community resources. Blue collar mortality in category I compared with category III was 2.1 times higher among black workers and 1.5 times higher among white workers. White collar mortality in category I compared with category III was 1.7 times higher among white workers. In addition, blue collar workers had substantially higher mortality compared with white collar workers in all occupational structure categories; about two times higher among blacks and about 1.8 times higher among whites.

Mortality was substantially higher among black compared with white men among blue collar workers in each occupational structure category, but was similar among white collar workers (table 2). Mortality ratios for black compared with white men in blue collar jobs, are inversely associated with occupational structure category; $1.8,1.5$, and 1.3 in category I, II, and III, respectively.

\section{DISCUSSION}

Occupational structure was chosen in this study as the primary characteristic for analysis as income is primarily distributed by means of work ${ }^{22}{ }^{23}$; therefore, distributions of jobs across communities represents a fundamental mechanism for distributions of income and other related social and economic resources. ${ }^{24-26}$ However, a community ecology does not represent a linear or hierarchical (causal) sequence, but should instead be viewed as a circular set of relations that influence and perpetuate each of the other characteristics; and these characteristics operate in relation to state, regional, national, and international economies. ${ }^{27}$ For example, the skills and education levels of a labour force reflects the current set of jobs in a community (table 1) and is an important factor in competing for relocating businesses and capital resources to initiate new business development in a community. ${ }^{28-32}$ Also, the diversity and availability of consumer services reflects occupational structure (that is, via local incomes) and is a factor in attracting additional skilled workers to relocate into a community. ${ }^{32}$ Thus, the ecological model conceptualises risk factors and CHD rates, occupational and industrial structure, consumer and producer services, and other aspects of community infrastructure to be highly interdependent. Therefore, we wish to describe how commonly these conditions coexist in communities and to better understand the relations between all of these community level characteristics and health outcomes including CHD mortality levels.

Higher CHD mortality among blue collar compared with white collar workers was shown in all occupational structure categories. Differential access and utilisation of beneficial community conditions among social class groups may reflect several advantages conferred by higher social class position, including income and wealth, occupational prestige and working conditions, social networks, and education levels. ${ }^{11} 34$ Such advantages influence coronary health ${ }^{35}$ through knowledge of coronary risk factors and motivation and resources to change practices ${ }^{36-39}$; ability to afford services, especially routine, health promotion services (for example, gym costs, preventive medical care); ability to afford comfortable, safe living conditions (for example, housing $\operatorname{costs}^{40}$ and healthy foods $\mathrm{s}^{4-43}$ ); amount of leisure time and time flexibility (for example, for exercise and the preparation of healthy foods $)^{44}$; higher job control and/or lower job demand (that is, lowered stress) ${ }^{45} 46$; adequate economic wealth (for example, savings) to provide for temporary periods of insufficient income. ${ }^{23}$ The inverse association between CHD mortality and occupational structure among all workers is consistent with increasingly

\section{Key points}

- Distributions of economic resources among communities is related to the organisation of work and geographical distributions of different types of jobs (occupational structure).

- Premature coronary mortality (CHD) decreased monotonically with improvements in overall community conditions/ infrastructure/services availability, among white collar and blue collar workers and among black men and white men.

- CHD mortality was lower among white collar compared with blue collar workers, and among white compared with black men, in each level of community conditions.

- CHD mortality among black compared with white men was only slightly higher among white collar workers and was substantially higher among blue collar workers, for each level of community conditions.

- Results suggest the importance of studying the occupational structure and geographical distributions of jobs as a fundamental cause of differences in community resources and conditions and related premature coronary mortality rates. Also, less access to locally available community resources among blue collar workers and African Americans may be a fundamental cause of higher coronary mortality among these groups.

beneficial community conditions for coronary health. However, white collar more than blue collar workers may have the necessary personal, social and economic resources to utilise available community services.

Occupational structure is an indicator of overall economic resources and services of communities but does not represent race and class residential patterns and differential access to services and living conditions within communities. Several studies provide evidence of differential opportunities for healthful living among neighbourhoods. Higher costs and fewer selections of foods, including fresh fruits and vegetables and low fat milk, have been reported for poorer compared with more affluent neighbourhoods. ${ }^{47-51}$ Targeted advertising of cigarettes and alcohol consumption to lower income neighbourhoods has also been reported. ${ }^{52} 53$

Table 3 shows indices of income inequality and class and race residential segregation for upstate NY counties in 1990. The scores for residential social class segregation reveal relatively low segregation in general and only modest differences in class segregation between occupational structure categories. In contrast, residential racial segregation seems high in all occupational structure categories. This score represents the percentage of the black population that would need to relocate so that census tracts reflect the percentage of county populations that are black, on average for counties in each occupational structure category. Therefore, at least 59\% of black populations would need to relocate to achieve residential racial integration in each occupational structure category, which suggests differential access to living conditions based on race.

Black, blue collar workers had the highest CHD mortality rates in all occupational structure categories, which may reflect greater vulnerability to effects of segregation in access to services and living conditions than among black, white collar workers. Racial residential segregation has been associated with adverse population health and racial differences in population health in previous studies. ${ }^{54}{ }^{55}$ In addition, in more rural areas such as occupational structure category I (table 1), the black population represented only $3 \%$ of the total population (table 2). Therefore, awareness of racism may be heightened and acts of discrimination more commonly experienced given the small black population in these areas. Also, occupational experiences of racism and discrepancies between expectations and actual experiences may be more apparent.

Income inequality scores were relatively low within each occupational structure category, ranging from 10 to 22 (table 3 ). 
Table 3 Income inequality, residential class, and race segregation indices by occupational structure category, Upstate New York Counties, 1990

\begin{tabular}{|c|c|c|c|}
\hline & \multicolumn{3}{|c|}{ Occupational structure category } \\
\hline & 1 & II & III \\
\hline Percentage of labour force in white collar occupations & $20-29$ & 30-39 & $40-50$ \\
\hline Income inequality index (\%)* & 18.2 & 10.4 & 22.3 \\
\hline Residential class segregation $(\%) \dagger$ & 13.6 & 18.8 & 21.3 \\
\hline Residential race segregation $(\%) \ddagger$ & 59.4 & 72.9 & 64.8 \\
\hline \multicolumn{4}{|c|}{$\begin{array}{l}\text { *Income inequality index: represents the share of total income that would need to be transferred from those } \\
\text { above the mean level of income to those below the mean, and therefore achieve equality in the distribution of } \\
\text { income. †Residential class segregation index: represents the percentage of "upper" white collar workers that } \\
\text { would need to change their census tract of residence so that all tracts reflect the overall percentage of } \\
\text { "upper" white collar workers in the county. County residential class segregation indices are population } \\
\text { weighted and combined into an overall residential class segregation index for each occupational structure } \\
\text { category (shown). } \ddagger \text { Residential race segregation index: represents the percentage of the black population } \\
\text { that would need to change their census tract of residence so that all tracts reflect the overall percentage of } \\
\text { black population in the county. County residential race segregation indices are population weighted by the } \\
\text { black population and combined into an overall residential race segregation index for each occupational } \\
\text { structure category (shown). }\end{array}$} \\
\hline
\end{tabular}

The income inequality score represents the share of total income that would need to be transferred from those above the mean income level to those below the mean level to achieve equality in the distribution of income. In 1990 the score for the United States was $30.2 \%$; state scores ranged from 27 to 34 , with a score of 33 for $\mathrm{NY}$ state overall. ${ }^{20}$ Occupational structure may represent the underlying cause of income inequality, which may be the reason for observing relatively low income inequality within categories, after stratifying on occupational structure.

The main limitations of this study were missing occupation information in the death certificate data and uncertainties about population denominator counts. In a sensitivity analysis, when decedents who were missing occupation information were analysed as blue collar workers, resulting CHD mortality rates showed very similar patterns to those shown in figure 1. Lower labour force participation among black compared with white men was observed in all occupational structure categories, however, substantially lower participation among black men (46\%) compared with white men ( $83 \%)$ was observed in category I ( table 1 ). However, workers in areas of chronic high unemployment, who are "discouraged workers" and have given up looking for a job are not considered to be unemployed and are not counted as part of the labour force. This is one explanation for the lower labour force participation among black people, especially among black men in occupational structure category I. Also, the incarcerated are included in county population counts, which is the denominator for the labour force participation calculation, but are not considered to be in the labour force (numerator value). When incarcerated populations are added to the numerator for the calculation of labour force participation, black labour force participation increases to $75 \%$, with little change for white men in occupational structure category I.

Higher premature mortality among blue collar compared with white collar workers and among black men compared with white men are consistent with previous studies. ${ }^{6}{ }^{12}$ Also, results showing effects of area resources on mortality levels and of social class and area resources ${ }^{1056} 57$ are consistent with the literature. However, in previous studies there has been an emphasis on isolating effects of individual class or area of residence, ${ }^{58}$ rather than on quantifying joint effects of class, race, and community conditions as presented in this study.

Results from large community based heart disease prevention trials, current theories of health education, as well as studies using occupational structure as a measure of community resources, indicate the need for a better understanding of how community social and physical environments impede or improve the coronary health of residents. To our knowledge and based on a search of the PubMed database, this study is the first to analyse joint effects of individual social class position, race, and community occupational structure on CHD mortality. Results from this study showed consistent beneficial effects of better community conditions on premature CHD mortality, but also revealed persistent excess mortality for less advantaged subgroups within communities (that is, by class and race). However, this study represented a limited geographical area (upstate New York). This approach needs to be replicated to ascertain the consistency of these results in other geographical localities and, therefore, to better understand policy implications suggested by these findings.

\section{Authors' affiliations}

D L Armstrong, D Strogatz, R Wang, Department of Epidemiology, SPH, University at Albany, SUNY, USA

E Barnett, Department of Epidemiology and Biostatistics, College of Public Health, University of South Florida, USA

Funding: this work was supported by a grant from the American Heart Association, New York State Affiliate, Inc. This research was conducted with support from the University at Albany, Center for Social and Demographic Analysis, and in conjunction with the Center for Minority Health Research, Education and Training. Dr Barnett was supported by a Scientist Development Grant from the American Heart Association.

Conflicts of interest: none.

\section{REFERENCES}

1 Wing S, Casper ML, Hayes CG, et al. Changing association between community occupational structure and ischaemic heart disease mortality in the United States. Lancet 1987; ii: 1067-70.

2 Casper ML, Wing S, Strogatz DS . Variation in the magnitude of black-white differences in stroke mortality by community occupational structure. J Epidemiol Community Health 1991;45:3-7.

3 Armstrong DL, Barnett E, Casper ML, et al. Community occupational structure, medical and economic resources, and coronary mortality among U.S. blacks and whites, 1980-88. Ann Epidemiol 1998:8:184-91.

4 Armstrong DL, Castorina JC. Community occupational structure, basic services, and coronary mortality in Washington state, 1980-94. Ann Epidemiol 1998:8:370-7.

5 Reynes J, Lasater T, Feldman $\mathrm{H}$, et al. Education and risk factors for coronary heart disease:results from a New England community. Am J Public Health 1993;9:365-71.

6 Marmot MG, Davey Smith G, Stansfeld S, et al. Health inequalities among British civil servants: the Whitehall II study. Lancet 1991:337:1387-93.

7 Connollay VM, Kesson CM. Socioeconomic status and clustering of cardiovascular disease risk factors in diabetic patients. Diabetes Care 1996; 19:419-22

8 Davey Smith G, Wentworth D, Neaton JD, et al. Socioeconomic differentials in mortality risk among men screened for the Multiple Risk Factor Intervention Trial: II. Black men. Am J Public Health 1996;86:497-504.

9 Davey Smith G, Neaton JD, Wentworth D, et al. Socioeconomic differentials in mortality risk among men screened for the Multiple Risk Factor Intervention Trial: I. White Men. Am J Public Health 1996;86:486-96. 
10 Davey Smith G, Hart C, Watt G, et al. Individual social class, area-based deprivation, cardiovascular disease risk factors, and mortality: the Renfrew and Paisley study. J Epidemiol Community Health 1998;52:399-405

11 Johnson JV, Hall EM. Class, work and health. In: Amick BC, Levine S, Tarlov AR, et al, eds. Society and health. New York: Oxford University Press, 1995.

12 Barnett E, Armstrong DL, Casper ML. Social class and premature mortality among men: a method for state-based surveillance. Am J Public Health 1997:87:1521-5.

13 Desenclos JCA, Hahn RA. Years of potential life list before age 65, by race, Hispanic origin, and sex-United States, 1986-1988. MMWR Morb Mortal Wkly Rep 1992;41:13-23

14 World Health Organisation. Manual of the international statistical classification of diseases, injuries and causes of death. Based on the recommendations of the Ninth Revision Conference, 1975. Geneva: WHO, 1977

15 National Center for Health Statistics. Public Use Data Tape Documentation, Mortality Detail, 1992 data. Hyattsville MD: National Center for Health Statistics, 1994 Dec.

16 Rothman KJ. Statistics in nonrandomized studies. Epidemiology 1990;1:417-18.

17 Greenland S. Randomization, statistics, and causal inference. Epidemiology 1990;1:421-9.

18 Kaufman JS, Cooper RS. Seeking causal explanations in social epidemiology. Am J Epidemiol 1999;150:113-28.

19 Census of Population and Housing, 1990: Summary Tape File 4 Technical Documentation/ prepared by the Bureau of the Census. Washington: The Bureau, 1993.

20 Kennedy BP, Kawachi I, Prothrow-Stith D. Income distribution and mortality: cross sectional ecological study of the Robin Hood index in the United States. BM 1996;312:1004-7.

21 Massey DS, Denton NA. Trends in the residential segregation of Blacks, Hispanics, and Asians: 1970-80. Am Sociol Rev 1987;52:802-25.

22 Albelda R, Drago R, Shulman S. Unlevel playing fields. Understanding wage inequality and discrimination. New York: McGraw Hill, 1997.

23 Oliver ML, Shapiro TM. Black wealth/white wealth. A new perspective on racial inequality. New York, NY: Routledge, 1997

24 usfeld DR; Bates T. The political economy of the urban ghetto. Carbonville and Edwardville IL: Southern Illinois University Press, 1984.

25 Falk WW, Lyson TA. High tech, low tech, no tech. Albany, NY: New York State University Press, 1988.

26 Squires, GD. Capital and communities in black and white: the intersections of race, class, and uneven development. Albany: State University of New York, 1994.

27 Taylor PJ. Political geography and the world-economy. In: Burnett AD Taylor PJ, eds. Political Studies from Spatial Perspectives. New York: John Wiley \& Sons Ltd., 1981.

28 Marshall, J. Services and uneven development. New York: Oxford University Press, 1988.

29 Cooper $\mathbf{R}$. The new economic regionalism: a rural policy framework. Ann Am Academy Political and Social Science 1993;529:34-47.

30 Noyelle T. Skills, wages, and productivity in the service sector. San Francisco, CA: Westview Press, 1990.

31 Daniels P. Service industries: growth and location. New York: Cambridge University Press, 1982.

32 Illeris S. The service economy. A geographical approach. New York Wiley, 1996

33 Lyson TA, Falk WW. Forgotten places, uneven development in rural America. Lawrence, KS: University Press of Kansas, 1993.
34 Bourdieu P. The forms of capital. In: Richardson JG, ed. Handbook of theory and research for the sociology of education. New York: Greenwood Press, 1986

35 Marmot M, Shipley M. Inequalities in death-specific explanations of a general pattern? Lancet 1984;i:1003-6.

36 Marmot MG, Kegevinas M, Elston MA. Social/economic status and disease. Annu Rev Public Health 1987:8:111-35.

37 White CC, Powell KE, Goelin GC, et al. The behavioral risk factor surveys, IV: the descriptive epidemiology of exercise. Am J Prev Med 1987;3:304-10.

38 Dishman RK, Sallis JF, Orenstein DR. The determinants of physical activity and exercise. Public Health Rep 1985;100:158-71.

39 Rimm IJ, Rimm AA. Association between socioeconomic status and obesity in 59,556 women. Prev Med 1974;3:543-72.

40 Ellaway A, Macintyre S. Does housing tenure predict health in the UK because it exposes people to different levels of housing related hazards in the home or its surroundings? Health and Place 1998;4:141-50.

41 Karp R, Greene GW. The effect of rising food costs on the occurrence of malnutrition among the poor in the United States: the Engels Phenomenon in 1983. Bull NY Acad Med 1983;59:721-7.

42 Travers KD. The social organization of nutritional inequities. Soc Sci Med 1996;43:543-53.

43 Ellaway A, Macintyre S. Shopping for food in socially contrasting localities. British Food J 2000;102:52-9.

44 Edginton CR, Jordan DJ, DeGraaf DG, et al. Leisure and life satisfaction. Dubuque, IA: Brown and Benchmark, 1995

45 Landsbergis PA, Schurman SJ, Israel BA, et al. Job stress and heart disease: evidence and strategies for prevention. New Solutions 1993; summer:42-58

46 Scott D. Longer hours, growth in service jobs stressing workforce, NIOSH Head says. News 1999;28:1224.

47 City of New York, Department of Consumer Affairs. The poor pay more for less. Part l: Grocery shopping. New York: April 1991

48 Consumers Union of US. The thin red line, How the poor still pay more. San Francisco, CA: West Coast Regional Office, 1993.

49 Fisher BD, Strogatz DS. Community measures of low-fat milk consumption: comparing store shelves and households. Am J Public Health 1999;89:235-7.

50 Sooman A Macintyre S, Anderson A. Scotland's health-A more difficult challenge for some? The price and availability of healthy foods in socially contrasting localities in the West of Scotland. Health Bull 1993;51:276-84.

51 Mooney C. Cost and availability of healthy food choices in a London health district. J Hum Nutr Diet 1990;3:111-20.

52 Williams JD, Achterberg C, Sylvester GP. Target marketing of food products to ethnic minority youth. Ann N Y Acad Sci 1993;699:107-14

53 Davis RM. Current trends in cigarette advertising and marketing. N Engl J Med 1987;316:725-32.

54 Polednak A. Segregation, discrimination, and mortality in U.S. blacks. Ethn Dis 1996:6:99-108.

55 Wacquant LJD, Wilson SJ. The cost of racial and class exclusion in the inner city. Ann Am Academy Political and Social Science 1989;501:8-25.

56 Yen IH, Kaplan GA. Neighborhood social environment and risk of death: multilevel evidence from the Alameda County Study. Am J Epidemiol 1999:149:898-907.

57 Jones S. Identifying deprived areas using indices from the 1991 census and information about the recipients of community charge and council tax benefit. J Epidemiol Community Health 1995;49:S65-71.

58 Macintyre S, Maciver S, Sooman A. Area, class and health: should we be focusing on places or people? J Social Policy 1993;22:213-34. 